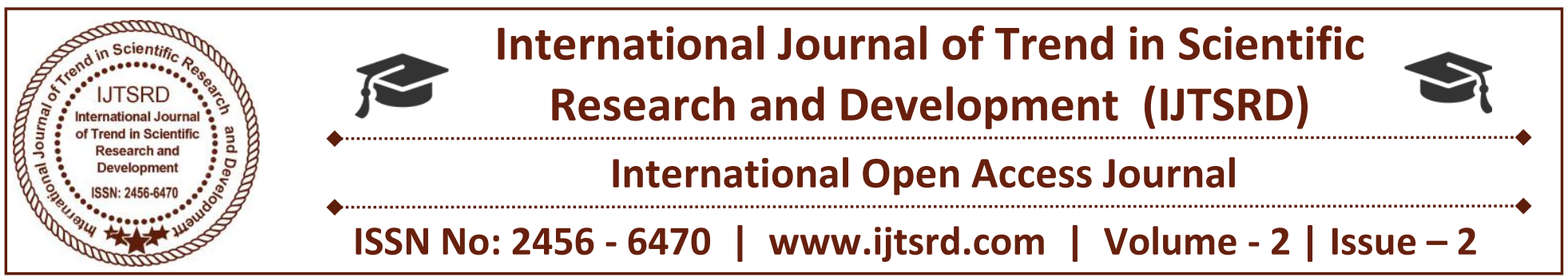

\title{
Knowledge regarding smoking hazards among adolescents
}

\section{Ms. Amandeep Kaur}

Staff Nurse, Fortis Memorial

Research Institute, Delhi, India

\author{
Mr. Atul Chaudhary \\ Assistant Professor, Himalayan \\ College of Nursing, SRHU, \\ Dehradun, India
}

\author{
Ms. Kanchan Bala \\ Senior Nursing Tutor, Himalayan \\ College of Nursing, SRHU, \\ Dehradun, India
}

\section{ABSTRACT}

Most smokers start smoking during their adolescence or early adult years. According to the World Health Organization (WHO), there are approximately 120 million smokers in India. Approximately 9 lakhs people die every year in India due to smoking. A Quasi experimental with one group pre-test post-test design study was conducted to assess the effectiveness of structured teaching Programme on smoking hazards among adolescents. Simple random technique was used to select 100 young adolescents and data was collected through structured knowledge questionnaire. The results revealed that mean percentage of posttest knowledge score $(14.75 \pm 1.38)$ was higher than the mean percentage of pre-test score $(7.04 \pm 1.43)$. Although there were no significant association found between selected demographic variables except friend smoking and family smoking with pre- test knowledge score at the level of $\mathrm{p}<0.05$. Hence the structured teaching Programme was significantly proved to be an effective method to improve the knowledge regarding smoking hazards among adolescent boys.

Keywords: Structured teaching Programme, Smoking hazards, Knowledge, Adolescents

\section{Introduction}

According to recent World health organization (WHO) an estimate of, 4.9 million deaths annually are attributed to tobacco consumption. Tobacco use is one of the major cause of death and disability worldwide; still it's being consumed by the people in all cadres. The emergence of tobacco related diseases are escalating public health problem. Health is considered wealth and wonderful gift to human kind. It's the duty of humans to preserve it to its fullest. ${ }^{1}$ Virtuous health is a priceless asset, but for some it's temporary pleasure causing them to fall into bad habits and ailments. ${ }^{1}$

According to WHO expert committee, Adolescent age is one of the most important and subtle period of one's life. The age period is defined between 10 to 19 years, the second decade of life. Adolescent age group usually tends to be considered under the categories of either youth or children. The actual interpretation of adolescence as a phase of life remains a social construct that differ between cultures. ${ }^{2}$

Damaging effects of cigarette smoking are abundant on health, which can lead to less effective quality of life besides illness in long run. Teenagers are fascinated by smoke and its style also tempts them to smoke. Friends and colleagues play a major role on non-smokers, to smoke for fun, or to show how much provocation they can have. Second-hand smoking or passive smoking effects are now prevalent and very few know them. Media can be considered more evident reason for motivating youngsters and teenagers to smoke. ${ }^{3}$

Smoking is considered the second major cause of death globally, which is currently considered responsible for the death of one in ten adults (about 5 million deaths each year). Current smoking can cause an average of 10 million deaths per year by 2020 . According to a 2010 report by the U.S. Centers for 
Disease Control and Prevention (CDC) nearly 20\% of adults smoke in the United States. More than $77 \%$ of them smoke every day. ${ }^{4}$

Cigarette smoking has become one of the public health issues as its causing cancer of mouth and upper respiratory system. Smoking among adolescents has also been reported to be associated with other unhealthy life styles such as alcohol consumption, illicit drug use and premarital unsafe sex. Adolescent smokers are also likely to be truant from school, an experience that may further jeopardize their future life. $^{5}$

\section{Methodology}

Quasi experimental study was led to assess the effectiveness of structured teaching programme on smoking hazards in terms of knowledge of adolescents, as India smoking is more prevalent among males so only males were included between the ages of 14 to 19 years, which were selected through simple random sampling technique form senior secondary school, Dehradun, Uttarakhand. Data was collected from 100 males with the help of self-prepared structured knowledge questionnaire consisting of-

Section A (Socio- demographic variables such as age, class, type of family ,residence, mother education, father education, father occupation, mother occupation ,income, do you smoke, do your friends smoke, is there anyone who smoke in your family.

Section B (consisting of 20 items related to Knowledge regarding smoking hazards)
The content validity of the tool was ensured by giving the tool to experts in the field of nursing and Medical. Reliability of tool was established by split half method following spearman brown formula. The reliability of tool was calculated and it was $r=0.93$.

\section{RESULT}

The results are organized according to the objectives of the study.

\section{Sample characteristics}

The data shown in table no- 1 depicts the percentage and frequency of demographic characteristics which shows that $(68 \%)$ participants fell between the age group of 14-16 years and (32\%) were in the age group of $17-19$ years. In the category of $9-10^{\text {th }}$ classes $49 \%$ boys were studying. Almost all (97\%) of the participants belonged to rural area and $58 \%$ were living in nuclear family. Regarding education of participants father only few $5 \%$ were no educated formally. Education of participant's mother showed that $9 \%$ were not educated formally. Occupation of father showed that 2\% were unemployed and $96 \%$ mother was home maker. Source of family income showed that almost half of the participant (47\%) were earning below Rs. 5000.

Among all the participants $(97 \%)$ were non-smokers and $(47 \%)$ of their friends were used to smoke. Family history of smoking showed that $35 \%$ of families had history of smoking.

Table No 1: Frequency and percentage distribution of socio- demographic Characteristics of the study participants

\begin{tabular}{|l|c|c|}
\hline $\begin{array}{l}\text { Demographic } \\
\text { characteristics }\end{array}$ & $\begin{array}{c}\text { frequency } \\
\text { (f) }\end{array}$ & $\begin{array}{c}\text { Percentage } \\
(\%)\end{array}$ \\
\hline Age( in year) & & \\
\hline a) $14-16$ & 68 & $\mathbf{6 8}$ \\
\hline b) $17-19$ & 32 & 32 \\
\hline Class & & 41 \\
\hline a) $9^{\text {th }}-10^{\text {th }}$ & 41 & $\mathbf{5 9}$ \\
\hline b) $11^{\text {th }}-12^{\text {th }}$ & 59 & 03 \\
\hline Area of living & & $\mathbf{9 7}$ \\
\hline a) Urban & 03 & \\
\hline b) Rural & 97 & \\
\hline Type of family & & \\
\hline
\end{tabular}


International Journal of Trend in Scientific Research and Development (IJTSRD) ISSN: 2456-6470

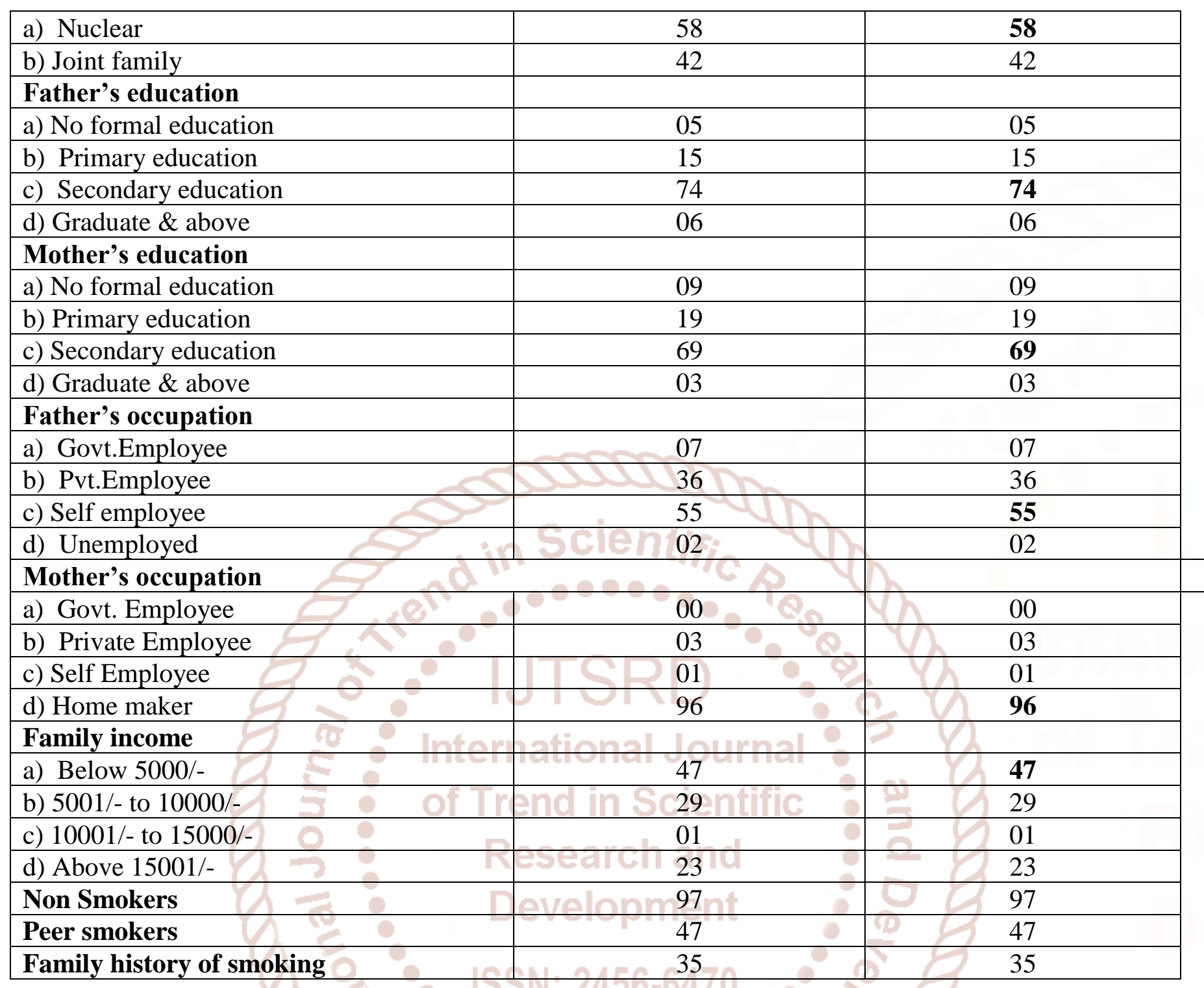

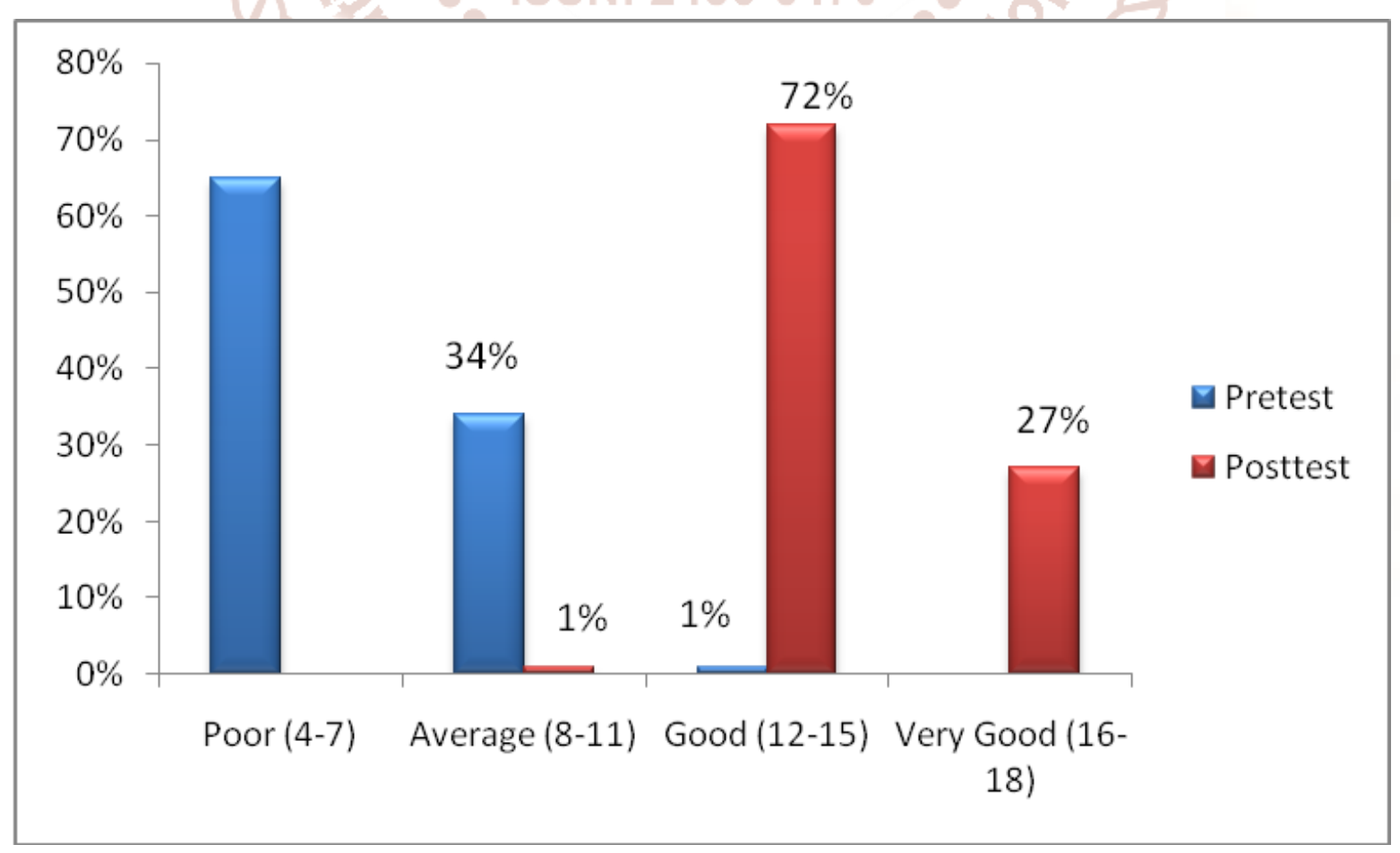

Figure no: 1 comparing the percentage of the adolescent boys according to the arbitrary scoring 
International Journal of Trend in Scientific Research and Development (IJTSRD) ISSN: 2456-6470

Data presented in figure no. 1; depicts the arbitrary scoring of knowledge score at pre-test and post-test level. In the pre-test majority of the adolescent boys $(65 \%)$ had poor level of knowledge and after intervention the posttest level showed and (72\%) had very good knowledge and no one scored under the category of poor.

Table no.2 Distribution of knowledge scores regarding smoking hazards among Adolescent boys.

\begin{tabular}{|l|l|l|l|}
\hline Knowledge Score & $\begin{array}{l}\text { Range } \\
\text { scores }\end{array}$ & Mean \pm SD & Mean percentage \\
\hline Pre-test & $4-12$ & $7.04 \pm 1.35$ & $35.2 \%$ \\
\hline Post- test & $11-18$ & $14.75 \pm 1.38$ & $73.75 \%$ \\
\hline
\end{tabular}

$\mathbf{N}=\mathbf{1 0 0}$

Table no. 2 revealed that range score for knowledge score at pre-test were (4-12) and post-test (11-18). The post-test mean knowledge score $(14.75 \pm 1.38)$ were apparently higher than the pre-test mean knowledge score $(7.04 \pm 1.43)$. The post-test mean percentages $(73.75 \%)$ were apparently higher than pre-test mean percentage $(35.2 \%)$.

\section{Effectiveness of STP regarding smoking hazards on the knowledge of adolescent boys}

Table no. 3 Effectiveness of STP regarding smoking hazards on the knowledge of adolescent boys

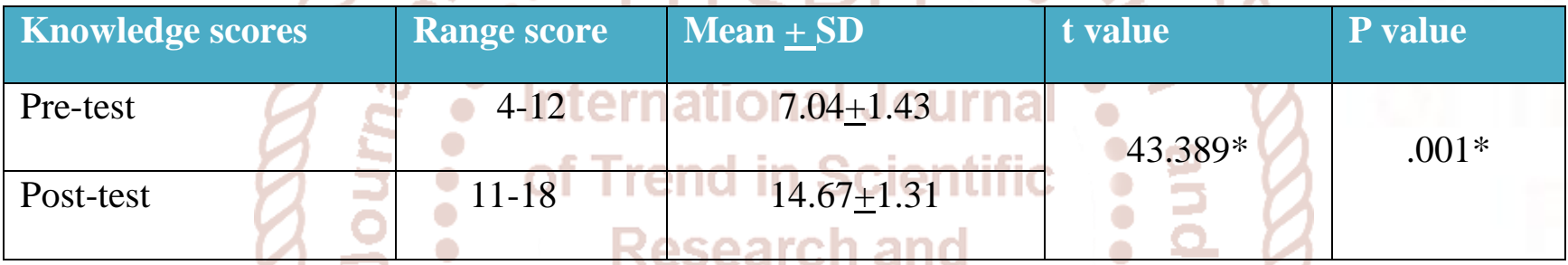

$\mathrm{df}_{99}=1.980$, at level of $\mathrm{p}<0.05$

*Significant

The data showed in Table no. 3 that mean of post test knowledge score $(14.67 \pm 1.31)$ were apparently higher than that of pretest mean knowledge score $(7.04 \pm 1.43)$. Hence the scores predicted that the significant difference between the mean of pre test and post test knowledge (7.63). The research hypothesis $\left(\mathrm{H}_{1}\right)$ was accepted as the difference of mean observed was of true difference it could be inferred that the structured teaching programme was an effective method to enhance the knowledge of adolescent boys regarding smoking hazards.

Association between selected socio-demographic variables with Pre-test levels of knowledge score among adolescent boys regarding smoking hazards.

Table no; 4 Association between Pre-test levels of Knowledge with selected demographic variable $\mathbf{N}=\mathbf{1 0 0}$

\begin{tabular}{|l|l|l|l|}
\hline Socio-Demographic Variables & $\begin{array}{l}\text { At \& above } \\
\text { Median }\end{array}$ & Below Median & $\chi^{2}$ cal value \\
\hline Peer Smokers & 11 & 36 & $\mathbf{5 . 2 4 ^ { * }}$ \\
Yes & 24 & 29 & \\
No & 07 & 28 & $5.32^{*}$ \\
\hline Family History of Smoking & 28 & 37 & \\
Yes & & & \\
No & &
\end{tabular}

df $1=3.84$ at level of $p<0.05$

* Significant 
The data showed in Table no. 4 that there was statistical significant association between level of knowledge score with age, peer smokers, family history of smoking at the level of $p<0.05$. Other

demographic variables like class, type of family, Residence, father education, mother education, father occupation, mother occupation, you smoke were not having any association with pre-test level of knowledge score at the level $\mathrm{p}<0.05$. Hence there was no evidence to reject null hypothesis for the variable, Peer smokers, and Family history of smoking. Hence, research hypothesis was accepted.

\section{DISCUSSION}

The purpose of the study was to assess the level of knowledge of adolescent boys about smoking hazards in senior secondary schools of Ranipokhri, Dehradun, Uttarakhand.

A total 100 adolescent boys were selected through simple random sampling .Pre- test was conducted by using self structured knowledge questionnaire. An structured teaching programme was conducted by the researcher. After seven days the post test was conducted by using the same structured knowledge questionnaire.

The structured teaching programme was conducted regarding smoking hazards, incidence, causes of smoking, harmful effect of smoking. The knowledge has increased in evidence of post- test score as compared to the pre-test.

The results revealed that mean percentage of posttest knowledge score $(14.75 \pm 1.38)$ was higher than the mean percentage of pre-test score (7.04 \pm 1.43$)$. Although there were no significant association found between selected demographic variables except friend smoking and family smoking with pre- test knowledge score at the level of $\mathrm{p}<0.05$. The research hypothesis $\left(\mathrm{H}_{1}\right)$ was accepted as the difference of mean observed was of true difference it could be inferred that the structured teaching programme was an effective method to change the knowledge of the adolescent boys regarding smoking hazards. The results were supported by the findings of the study conducted by Bhuvanesh Shukla ${ }^{6}$ to assess the effect of structured teaching programme on knowledge among adolescent boys regarding ill effects of smoking.

\section{CONCLUSION}

Based on the findings of the study, it can be concluded that most of the adolescents had good knowledge regarding smoking hazards. From the finding of the study it can be concluded that most of the adolescent boys $(65 \%)$ had poor level of knowledge, $34 \%$ adolescents showed average level of knowledge and only one percent adolescent boys had good level of knowledge at pre-test and $72 \%$ had good level of knowledge at post-test level and $27 \%$ had very good knowledge and only $1 \%$ had average knowledge at post-test level.

\section{REFERENCES}

1. Sidaveerappa Balappa Tuppad. ill effects of smoking on health .[cited on jan 2 2016]; Available from: https://www.ljubljuknigi.ru/store/ru/book/illeffects-of-smoking-on-health/isbn/978-3-84658763-8.

2. Adolescence Period.2015[cited on 10 jan 2016]; Available From: http://en.wiki pedia.org/wiki/Pediatrics access date:3/4/15.

3. Smoking and adolesents.2007[Cited on dec 20 2015]; Available from: http://en.wikipedia.org/wiki/smoking and adolescent

4. Sinha D1. N, Reddy KS, Rahman K, Warren CW, Jones NR, Asma S. Linking Global Youth Tobacco Survey (GYTS) data to the WHO framework convention on tobacco control: the case for India. Indian J Public Health2006[cited on $0 \mathrm{ct} \quad 26 \quad$ 2015];Available from:www.ncbi.nlm.nih.gov/pubmed?cmd=Link\& LinkName=pubmed...uid.

5. Rani M, Bonu S, Jha P, Nguyen S, Jamjoum L. Tobacco use in India: Prevalence and predictors of smoking and chewing in national cross sectional household survey.Tob Control 2003;12:e4, 1-8.

6. Bhuvanesh Shukla Dr., Kaur Urvinder knowledge regarding ill effects of smoking. international research journal.2014[cited on dec.2015 from 24];vol

4(1):availablefrom:http://irj.iars.info/volumes/828 004012014/pdf/82800401201402.pdf. 